\title{
Mapeamento de ações coletivas de ocupação urbana: uma análise etnofotográfica
}

\author{
Mapping collective actions of urban occupation: an ethno \\ photographical analysis
}

http://dx.doi.org/10.5007/2178-4582.2016v50n1p106

\author{
Adolfo Pizzinato, Cristiano Hamann, Ezequiel Simonetti Cargnelutti \\ Roberta Iankilevich Golbert, Lígia Burton-Ferreira \\ Pontifícia Universidade Católica do Rio Grande do Sul, Porto Alegre/RS, Brasil \\ e Rodrigo Oliveira-Machado \\ Universitat Autònoma de Barcelona, Barcelona, España
}

\begin{abstract}
Esta pesquisa teve o objetivo de mapear ações de ocupação do espaço público em Porto Alegre, assim como compreender aspectos do funcionamento destas formas de ação. Para tanto, a investigação guiou-se a partir de três etapas simultâneas: o levantamento de informações através da mídia e redes de relacionamento; a observação de ocupações; o estabelecimento de contato com participantes e a realização de entrevistas, auxiliadas por uma proposta de produção etnofotográfica estabelecida previamente. A partir destes procedimentos de coleta de dados, pôde-se estabelecer um panorama de temáticas que figuram em ocupações urbanas, locais e rotas utilizadas, formas de divulgação e organização dos eventos, assim como discutir aspectos vinculados ao público envolvido. As ocupações urbanas etnografadas emergem como possibilidades muito diversificadas de dissenso político e ressignificação, em sintonia com as novas formas de organização social, em que a internet e a flexibilidade de papéis sociais despontam como tônica dessas ações.
\end{abstract}

Palavras-chave: Ocupação Urbana; Ações Coletivas; Movimentos Sociais.
This study aims to map occupation actions of public space in Porto Alegre, as well as to understand aspects of the operation of these political actions. Therefore, the research was guided from three simultaneous steps: collecting information through the media and social networks; observation of occupations; direct contact and interviews with the participants, aided by a proposal of an ethno photographical production arranged in advance. From these data collection procedures, it was possible to establish an overview of themes contained in urban occupations, sites and routes used, forms of dissemination and organization of the events, and also to discuss aspects of the public involved. The ethnographied urban occupations emerge as highly diversified possibilities of political dissent and reinterpretation, in tune with new forms of social organization in which the Internet and the flexibility of social roles appear as keynotes of these sort of public actions

Keywords: Urban Occupation; Collective Actions; Social Movements

\section{Introdução}

Etnografar movimentos de ocupação no espaço urbano é um desafio que supõe uma série questões éticas e metodológicas. As cidades, espaços que suscitam vivências e memórias plurais - por vezes subversivas e criadoras, por vezes tradicionais, assimétricas e vinculadas a abusos de poder - demandam do transeunte/militante/etnógrafo uma dupla disposição: ter nos espaços urbanos o cenário de suas indagações e estranhamentos, assim como trans- 
formá-los em objetos de sua própria reflexão. Em um movimento contrário ao da naturalização das transformações sociais expressas na cidade, algumas possibilidades analíticas apresentam-se de forma consonante com a perspectiva etnográfica. Marc Augé (1992), por exemplo, na diferenciação entre os conceitos de lugar antropológico e não lugar propõe a tomada de consciência deste processo histórico de modificação das formas de organização social, econômica e simbólica da sociedade. Enquanto lugar antropológico (AUGÉ, 2011), a cidade põe em pauta uma multiplicidade de formas de ser - sentir e identificar-se - em um processo sempre aberto de encontros e interações (HIERNAUX, 2006). Entretanto, enquanto não lugares, certos espaços da cidade dissolvem-se no campo do não sentido e na possibilidade de brutalização da vida pela perda de significados compartilhados na cidade (SÁ, 2014).

No entanto, considerar as ocupações do espaço urbano no Brasil contemporâneo suscita um lócus de análise sujeito a muitas interpretações - seja em função do estranhamento em relação às formas de organização, seja em relação à evidente pluralidade de temáticas emergentes. Esse contexto, ao passo que mostra um espaço de comunicação social complexo (por exemplo, se considerarmos o impacto das $\mathrm{TIC}^{1}$ nesse processo), permite que se discutam as maneiras de se comunicar e significar-se pelos eventos urbanos. Não se sustentam, evidentemente, numa noção tradicional (meramente geográfica) de território - enquanto campo concreto de relações - mas, sim, em interfaces contemporâneas de interlocução que ultrapassam formas tradicionais de pertencimento e participação social. Essas interfaces permitem transgressões e a abertura de certas "fissuras" nos sistemas de dominação circunscritos na (e da) cidade, sendo palco de movimentos urbanos e do despontar de manifestações civis das mais diversas ordens e com uma grande variedade de reivindicações e demandas (UGLIONI; DUARTE, 2011).

Para compreender estas manifestações, apresentam-se neste estudo alguns eixos teóricos iniciais, como: as interlocuções entre a concepção de movimentos sociais tradicionais e as ações atuais de ocupação; a noção de cidade e espaço urbano a partir da articulação com o espaço virtual; e o mapeamento etnofotográfico como possibilidade de significação das formas de se relacionar e dar sentido aos espaços da cidade.

\section{Da cidade e suas possibilidades de subversão}

A pluralidade de opiniões e reivindicações, assim como as possibilidades de identificação e pertencimento a grupos ou pautas sociais - por vezes am-

$\overline{1}$ Tecnologias de Informação e Comunicação. 
bíguas e conflituosas - indicam novas formas de interação social, inclusive no Brasil contemporâneo. Este complexo panorama remete a uma forma dinâmica de ser e se relacionar, intrinsecamente vinculada à globalização. Seja em relação à velocidade dos processos comunicacionais (VIRILIO, 1993), à dita liquidez (ou fluidez) das relações psicossociais (BAUMAN, 2005; 2009), ou ao consumo como atravessador social (LIPOVETSKY, 2007), notam-se mudanças a nível mundial - principalmente após a década de 1960 do século XX. Esse contexto plural nos remete às diferentes possibilidades de ser na cidade e põe em pauta os discursos sociais que se corporificam numa interface entre processos de participação e identificação com causas coletivas; os movimentos e as formas de significar o espaço urbano; e a interface potente da noção de cidade e de espaço virtual quando da discussão de manifestações populares.

Esta tentativa de resgate de informações e orientação para a compreensão das ações coletivas no Brasil contemporâneo exige que se localizem historicamente algumas mudanças emergentes nesse âmbito de experiência social. $\mathrm{O}$ ano de 2011 parece particularmente importante quando nos debruçamos sobre estas questões, principalmente quando o situamos num processo global de eventos sociais de repercussão midiática em diferentes partes do globo (HARVEY et al., 2012). É interessante notar o papel das mídias nesse processo, visto por uma perspectiva discursiva, já que põe em pauta formas e expectativas diferentes em relação ao que se compreende tradicionalmente como movimento social. Cabe a pergunta: Que articulação acontece, neste momento histórico e espaço-temporal brasileiro, entre agendas e pautas locais e estas formas de solidariedade e partilha global?

Nesta dimensão global de interação, na qual a cidade torna-se um palco complexo de análise, é difícil não nos referirmos às ressonâncias mundiais anteriores. No continente africano, na derrubada de regimes políticos na Tunísia, Egito, Líbia e Iêmen; nos territórios europeus, com ocupações e greves como as acontecidas na Espanha e Grécia, revoltas no subúrbio de Londres; ações coletivas em ocupações na Wall Street, nos EUA; ou nos eventos ocorridos na Rússia (CARNEIRO, 2012). Exemplos de movimentações e possibilidades de interlocução interpelados pelas possibilidades das mídias e circunscritas a um período histórico que, ainda que delimitado à análise, carrega uma memória acerca das possibilidades de ativismo, reivindicação, subversão que acompanham gerações e memórias sociais.

No Brasil, estas formas de interação urbana e possibilidade de exercícios de cidadania - possíveis espaços simbólicos de emancipação e fazer político (RANCIÈRE, 2010) - tomam maior visibilidade nas ocupações desencadeadas em Junho de 2013. Waisbich (2013), ao circular pelas ocupações de Junho 
de 2013, nota que as reivindicações sociais percebidas em sua etnografia se configuravam no que denomina "algo estranhamente festivo". Uma percepção que denomina como um "estranhamento", configuração e comportamentos que parecem destoar das representações de manifestações reivindicatórias mais tradicionais do século XX. A sensação de festejo, neste contexto, quebra o curso ordinário da vida cotidiana ou corrobora o que Minois (2003, p. 602) denomina de "atmosfera de festa permanente" tipicamente contemporânea? Como operacionalizar e desenvolver uma forma de compreender essas ocupações cujas características são a fugacidade espaço-temporal e a potência subversiva-política?

$\mathrm{Na}$ discussão sobre este complexo panorama social, compreendemos que a noção de ação coletiva é mais apropriada do que a de movimentos sociais, pois entendemos, como Diani (1992), que os movimentos sociais são constituídos por vínculos firmes e possuem alvos específicos, ao passo que as ações que descrevemos aqui possuem uma identificação menos estável e mais fugaz - mesmo que com potencial de institucionalização presente. Devido ao grande número de movimentos, e à sua complexidade, a preferência pelo termo "ações coletivas" se justifica pela amplitude que este conceito abarca, ao contrário da conceituação de movimentos sociais.

Além da questão da definição formal de que tipos de eventos eram analisados, fica clara a necessidade de uma definição dos espaços e lugares por eles ocupados - sejam geográficos ou virtuais. A insuficiência de uma noção concreta de espaço para lidar com suas dimensões mais subjetivas (e também no que se refere ao papel das comunicações virtuais), também deve compor a compreensão de cidade. Portanto, pode ser útil o emprego de diferenciações de lugar e não-lugar (AUGÉ, 2011) nesta argumentação. Estas instâncias contemporâneas da urbe, ao mesmo tempo que se constituem em coexistência, chamam a atenção para estados de atribuição de sentido e vivências humanas diferentes. Enquanto os lugares compreendem uma relação forte entre os aspectos sociais e o espaço físico, de forma a promover identificações e interlocuções, os não-lugares seriam espaços físicos caracterizados pela emergência de certo 'mecanicismo' em que o objetivo não está no espaço, e sim em alguma meta além dele (Id.,Ibid.). Esses não-lugares são espaços de pouca troca relacional, de transição e movimentação e circulação fugaz de indivíduos que não têm a preocupação promover sentimentos de pertença ou afiliação, apenas utilizam o local como via de transição.

A partir desse recorte temático - do exercício de compreensão das possibilidades de ocupação que se forjam nas ruas - pensamos a cidade como um palco de visibilidade e tensionamento. Pensar a cidade nesse âmbito é conceber a multiplicidade e diversidade que compõem o urbano - cidades polifônicas, 
que nos surpreendem pelas possibilidades de vozes, papeis e posicionamentos possíveis. Nesse panorama de tensões (entre questões de centro e periferia, existência de aglomerados urbanos e problemas de circulação nas cidades), assim como problemas em geral não ressaltados (como a funcionalidade da urbe quando se fala das necessidades subjetivas da população), estabelecemos alguns questionamentos - elencando como lócus de análise, ações coletivas atuais de ocupação urbana.

Pretendeu-se, inicialmente, compreender quais eram e como atuavam as ações de ocupação urbana da esfera pública de Porto Alegre, abrangendo movimentos institucionalizados e ações coletivas não institucionalizadas entre março de 2013 e dezembro de 2014. Partiu-se de uma premissa dialógica de que tanto os participantes diretamente implicados nas ações coletivas, quanto sua audiência, possuíam papéis funcionais na produção e significação destas ocupações. Neste sentido, o entendimento desta realidade social e suas interfaces com o espaço urbano pareceram potentes se analisados a partir de uma pesquisa participativa e etnográfica.

\section{Método}

Esta pesquisa foi delineada com o objetivo de mapear ações de ocupação do espaço público em Porto Alegre, assim como compreender aspectos do funcionamento destas ações de ocupação. Para tanto, a investigação guiou-se a partir de três etapas, que aconteciam simultaneamente: o levantamento de informações através da mídia e redes de relacionamento; a observação de ocupações e o estabelecimento de contato com participantes e observadores na rua; e a realização de entrevistas, auxiliadas por uma proposta de produção fotográfica estabelecida previamente com os entrevistados.

O levantamento de informações pelas redes de comunicação, em especial as digitais e o Facebook, foi escolhido por representar um tipo de organização amplamente utilizada e já apontada por estudiosos da área (CASTELLS, 2012). Mostrou-se, portanto, uma alternativa viável para acompanhar o andamento dos movimentos dos coletivos e recolher informações diversas, como: locais onde seriam realizadas as ocupações, pautas, comentários e possíveis lideranças envolvidas. Além da dimensão virtualizada da pesquisa, os pesquisadores fizeram observações etnográficas de parte destas ocupações. Destas observações, geraram-se diários de campo, entrevistas narrativas e produções etnofotográficas de todos os segmentos envolvidos (transeuntes, militantes/ organizadores e pesquisadores).

No momento das ocupações, os pesquisadores escolhiam, por conveniência, participantes que desejassem fazer uma produção fotográfica sobre o 
que vivenciassem. Consistia em duas etapas: no momento das ocupações, os pesquisadores forneciam uma máquina descartável de 27 poses para que o participante fizesse um ensaio representativo da sua experiência; posteriormente, esse mesmo participante era convidado a dar uma entrevista sobre a sua participação, tendo como referência o material fotográfico produzido. As entrevistas se davam de forma aberta e com caráter narrativo, e sua análise buscou integrar aspectos da percepção dos participantes sobre o itinerário desenvolvido ao longo da ocupação urbana. Caso não aparecessem de forma espontânea, alguns eixos eram propostos nas abordagens, por exemplo: Como é o público para quem a ocupação foi realizada? Que objetivos, metas ou missões você acredita estarem presentes na ocupação? Quais os aspectos que tu consideras motivacionais para a sua participação? Tu achas que existem discrepâncias entre o que é verificado na ocupação e a tua opinião?

Nesta abordagem, a fotocomposição foi assumida como uma proposta de aproximação metodológica que se dispõe a operar enquanto forma de apreensão da significação que os(as) participantes fazem do acontecimento e seus significados. A escolha da produção de imagens se deve a seu potencial enquanto forma alternativa de linguagem em pesquisa, permitindo a apreensão de aspectos subjetivos que possivelmente não estariam presentes em entrevistas tradicionais. Neste sentido, a produção fotográfica desponta como possibilidade de explorar espaços de autoria para os participantes da pesquisa.

Tal aproximação metodológica se constituiu nos moldes defendidos por Maurente e Tittoni (2007), e Pizzinato (2008), em que a fotografia aperfeiçoa aspectos de expressão não tão diretamente apreendidos pelo discurso verbal e instrumentaliza o processo de construção da entrevista narrativa. Segundo Banks (2009), a produção de narrativas visuais se define como uma organização intencional de informações, desta maneira, os materiais devem ser entendidos como estruturas comunicativas. Neste sentido foi proposto que, além de elaborar considerações sobre as fotografias isoladamente, o entrevistado estabelecesse sentidos para a construção da série fotográfica como um todo, seja estabelecendo ordens de importância, temporal, ou da forma que achasse mais significativo apresentar na entrevista.

\section{Resultados e discussão}

Diversos aspectos emergiram do processo etnofotográfico realizado ao longo da pesquisa. Inicialmente, descrevemos as pautas declaradas pelas ações coletivas, que remetem ao panorama de temáticas em Porto Alegre; locais e rotas principais utilizadas; posteriormente discutimos as formas de di- 
vulgação e percepção dos participantes sobre estes aspectos comunicacionais; e, por fim, elaboramos algumas considerações sobre o público envolvido nas manifestações acompanhadas.

Foram mapeados, pelo Facebook, 264 eventos, que ocorreram entre de março de 2013 a dezembro de 2014. Destes eventos, considerando as limitações logísticas e a diversidade de temáticas, os pesquisadores estiveram presentes em 56 deles. Destes 56 eventos, em 16 houve o registro fotográfico e entrevista com algum participante ou organizador e nos demais houve o registro de diário de campo, com ou sem tomada fotográfica. Ao nos depararmos com a amplitude de temáticas e modelos de ações encontradas, operamos uma análise temática (FLICK, 2009) de seu material digital, contrastado pela presença física nos eventos (quando possível).

A análise desse material fez com que chegássemos ao material apresentado no Quadro 1 - 13 categorias de eventos mapeados, com ao menos 2 eventos em cada categoria. Alguns desses eventos tiveram caráter efêmero (ou de happening), enquanto outros promoveram vários encontros (como o Bloco de Lutas, por exemplo). Entretanto, para fins de análise nesta pesquisa, considerou-se cada novo "evento" promovido através do Facebook como um novo evento, ainda que promovido por um mesmo coletivo. Em alguns eventos, havia pautas ou convocações de interface entre diferentes categorias mapeadas - como, por exemplo, nos eventos Largo Vivo! Em defesa da alegria e da diversidade de orientação sexual! e Largo Vivo sem Tatu!", nos quais a promoção artística dividia bandeira com a diversidade sexual e de gênero e com protestos contra o Mundial de Futebol. Nesses casos, os eventos foram enquadrados em apenas uma das categorias, considerando os desdobramentos de comentários no próprio Facebook.

Quadro 1. Síntese do mapeamento via Facebook dos eventos de ocupação coletiva da cidade de Porto Alegre (2013-2014)

\begin{tabular}{|c|c|c|c|}
\hline Categorias & Definição & Exemplos de eventos & Número \\
\hline $\begin{array}{l}\text { Promoção } \\
\text { Cultural e } \\
\text { Artística }\end{array}$ & $\begin{array}{l}\text { Enfatizavam a confra- } \\
\text { ternização e agrupação } \\
\text { social através da promo- } \\
\text { ção de pautas artísticas, } \\
\text { musicais, teatrais ou } \\
\text { explicitamente festivas. }\end{array}$ & $\begin{array}{l}\text { "Largo Vivo - a rua é } \\
\text { pra dançar! <o/ lo_lo/ } \\
\text { o/ } \mid \text { o > "; "FESTA EM } \\
\text { LA CALLE - Quando os } \\
\text { de BAIXO bailam, os de } \\
\text { cima caem" }\end{array}$ & 64 \\
\hline
\end{tabular}




\begin{tabular}{|c|c|c|c|}
\hline $\begin{array}{l}\text { Ocupação } \\
\text { Territorial } \\
\text { e predial }\end{array}$ & $\begin{array}{l}\text { Ênfase na ocupação } \\
\text { definitiva ou temporária } \\
\text { de áreas ou espaços } \\
\text { urbanos públicos ou } \\
\text { privados, degradados, } \\
\text { abandonados ou que } \\
\text { operavam alguma } \\
\text { medida de exclusão } \\
\text { social. }\end{array}$ & $\begin{array}{l}\text { "Largo Vivo - Ocupando } \\
\text { a Cidade!"; "Ato de Re- } \\
\text { sistência à Reintegração } \\
\text { de Posse do Loteamento } \\
\text { São Luiz" }\end{array}$ & 57 \\
\hline $\begin{array}{l}\text { Transpor- } \\
\text { te }\end{array}$ & $\begin{array}{l}\text { Contra o aumento das } \\
\text { passagens de transporte } \\
\text { público e pela promoção } \\
\text { de sua qualidade, além } \\
\text { de formas alternativas de } \\
\text { locomoção. }\end{array}$ & $\begin{array}{l}\text { "Marchas contra o au- } \\
\text { mento das passagens"; } \\
\text { "Massa crítica" }\end{array}$ & 34 \\
\hline $\begin{array}{l}\text { Contes- } \\
\text { tação do } \\
\text { Estado }\end{array}$ & $\begin{array}{l}\text { Mobilizações contrárias } \\
\text { à diferentes Políticas de } \\
\text { Estado e, também em } \\
\text { relação à sua própria } \\
\text { existência. }\end{array}$ & $\begin{array}{l}\text { "Protesto não é crime! } \\
\text { Ato unificado contra a } \\
\text { criminalização das lutas } \\
\text { populares!"; "Hoje vai } \\
\text { ser maior! Tribuna Po- } \\
\text { pular e Largo Vivo! Vem } \\
\text { pra luta contra o aumen- } \\
\text { to e contra a lei geral" }\end{array}$ & 27 \\
\hline $\begin{array}{l}\text { Contes- } \\
\text { tação do } \\
\text { modelo } \\
\text { capitalista } \\
\text { e de con- } \\
\text { sumo }\end{array}$ & $\begin{array}{l}\text { Contra ao modelo de } \\
\text { sociedade vigente, espe- } \\
\text { cialmente em relação ao } \\
\text { consumo e à exclusão } \\
\text { socioeconômica. }\end{array}$ & $\begin{array}{l}\text { "Feira Nômade } 1^{\circ} \text { Edi- } \\
\text { ção !"; "Largo VIVO } \\
\text { sem Tatu!" }\end{array}$ & 22 \\
\hline $\begin{array}{l}\text { Copa do } \\
\text { Mundo de } \\
\text { Futebol }\end{array}$ & $\begin{array}{l}\text { Especificamente contrá- } \\
\text { rias às ações políticas } \\
\text { em relação ao Mundial } \\
\text { de Futebol na cidade. } \\
\text { Desde obras às ações de } \\
\text { segurança pública. }\end{array}$ & $\begin{array}{l}\text { "GRANDE ATO - DIL- } \\
\text { MA EM PORTO ALE- } \\
\text { GRE: Não vai ter Copa, } \\
\text { vai ter luta"; "ATO: } \\
\text { Quinta Feira é PASSE } \\
\text { LIVRE e COPA PRA } \\
\text { QUEM?" }\end{array}$ & 19 \\
\hline
\end{tabular}




\begin{tabular}{|c|c|c|c|}
\hline $\begin{array}{l}\text { Diversida- } \\
\text { de sexu- } \\
\text { al e de } \\
\text { gênero }\end{array}$ & $\begin{array}{l}\text { Em prol de ações afir- } \\
\text { mativas e em defesa } \\
\text { dos direitos vinculado à } \\
\text { diversidade sexual e de } \\
\text { gênero }\end{array}$ & $\begin{array}{l}\text { "Direito à identidade: } \\
\text { Viva Seu Nome - 4a Edi- } \\
\text { ção"; "Beijaço Contra a } \\
\text { Homofobia - \#FORAFE- } \\
\text { LICIANO" }\end{array}$ & 17 \\
\hline $\begin{array}{l}\text { Ambien- } \\
\text { talistas }\end{array}$ & $\begin{array}{l}\text { Ações em promoção } \\
\text { da qualidade de vida, } \\
\text { da proteção de espaços } \\
\text { verdes, de ciclovias, de } \\
\text { feiras ecológicas, dos } \\
\text { pedestres e ciclistas. }\end{array}$ & $\begin{array}{l}\text { "II Pedalada Pelada } \\
\text { de Porto Alegre"; “(R) } \\
\text { Existência das Árvores } \\
\text { do Gasômetro - É A } \\
\text { HORA!" }\end{array}$ & 15 \\
\hline $\begin{array}{l}\text { Feminis- } \\
\text { tas }\end{array}$ & $\begin{array}{l}\text { Em defesa de pautas } \\
\text { feministas e em defesa } \\
\text { de direitos da mulher. }\end{array}$ & $\begin{array}{l}\text { "Marcha das Vadias de } \\
\text { Porto Alegre"; "Dia de } \\
\text { luta pela legalização do } \\
\text { aborto e contra o Estatu- } \\
\text { to do Nascituro em Porto } \\
\text { Alegre" }\end{array}$ & 10 \\
\hline $\begin{array}{l}\text { Direitos } \\
\text { Humanos }\end{array}$ & $\begin{array}{l}\text { Pela promoção de novos } \\
\text { direitos sociais e na ma- } \\
\text { nutenção de direitos já } \\
\text { conquistados em diferen- } \\
\text { tes campos. }\end{array}$ & $\begin{array}{l}\text { "Marcha da Maconha } \\
\text { Porto Alegre 2013"; "3º } \\
\text { ATO DE REPUDIO A } \\
\text { NOMEAÇÃO DO PAS- } \\
\text { TOR MARCO FELI- } \\
\text { CIANO PARA CDHM" }\end{array}$ & 5 \\
\hline $\begin{array}{l}\text { Alimen- } \\
\text { tação e } \\
\text { Culinária }\end{array}$ & $\begin{array}{l}\text { Atos de promoção de } \\
\text { novos hábitos de produ- } \\
\text { ção, comercialização e } \\
\text { consumo alimentar, além } \\
\text { de promoção de culinária } \\
\text { popular. }\end{array}$ & $\begin{array}{l}\text { “Comida de Rua: A Feira } \\
\text { \#2"; "Feira Nômade } 1^{\circ} \\
\text { Edição!" }\end{array}$ & 4 \\
\hline $\begin{array}{l}\text { Política } \\
\text { Interna- } \\
\text { cional }\end{array}$ & $\begin{array}{l}\text { Contra conflitos e ocupa- } \\
\text { ções territoriais interna- } \\
\text { cionais. }\end{array}$ & $\begin{array}{l}\text { "NÃO EM NOSSO } \\
\text { NOME! FORA ELBIT } \\
\text { - Intervenção cênica e } \\
\text { panfletagem em solidar"; } \\
\text { "DCE PUCRS convida: } \\
\text { ato e lançamento do Co- } \\
\text { mitê Estudantil Palestina } \\
\text { Livre: FORA ELBIT DO } \\
\text { BRASIL" }\end{array}$ & 2 \\
\hline
\end{tabular}




\begin{tabular}{|l|l|l|c|}
\hline $\begin{array}{l}\text { Etnici- } \\
\text { dade e } \\
\text { racismo }\end{array}$ & $\begin{array}{l}\text { Em defesa de coletivos } \\
\text { vítimas de racismo e na } \\
\text { promoção da diversidade } \\
\text { étnico-racial. }\end{array}$ & $\begin{array}{l}\text { "RESISTÊNCIA ÉT- } \\
\text { NICA E A LUTA POR } \\
\text { TERITÓRIOS NO RS" }\end{array}$ & 1 \\
\hline
\end{tabular}

Fonte: elaborado pelos autores

Em Porto Alegre, percebe-se a influência de tais protestos na atuação de grupos que se propõem a ocupar espaços urbanos com diferentes motivações e implicações, apresentando temas da cidade. Na pauta dos diversos eventos porto-alegrenses figuram questões de gênero e identidades sexuais não hegemônicas, críticas à desigualdade socioeconômica, temáticas ambientalistas e contestação à privatização de espaços públicos, entre outras. Dentre essas ações coletivas, destacam-se ainda movimentos organizados, mais institucionalizados, como Defesa Pública da Alegria, RUA - Rastro Urbano de Amor e Largo Vivo, que promoveram ocupações pautadas por manifestações artísticas; Okupa Viaduto, com ocupações no viaduto da Avenida Borges de Medeiros, todas as terças-feiras; PortoAlegre.cc, de cunho mais institucional, revitalizando parques no horário noturno; Batalha do Mercado, realizando, no último sábado de cada mês, um torneio de hip-hop no centro da cidade; Marcha das Vadias, passeata feminista anual que luta pela igualdade de gênero; Massa Crítica, originada em Setembro de 1992, em San Francisco, e difundida pelo resto do mundo, onde ciclistas manifestam-se em prol de formas alternativas de trânsito, além de manifestações baseadas na grafia urbana, como PIXEyLUTE, grupo de pichadores engajados em intervenções de cunho social; e como Maiorais e Insônia que, por meio de pichações evidenciam fortes questões identitárias de pertencimento grupal e de afiliação ideológica.

No que se refere, especificamente, aos locais destinados às ocupações, citados nas entrevistas, evidencia-se uma diferenciação corriqueira entre espaços da cidade em relação ao impacto da manifestação, adesão de participantes, e possibilidades de interlocução. Em geral, quando as ocupações não tinham, declaradamente, o objetivo de ressignificar o uso de determinado espaço público - principalmente na iminência de privatizações - elas se concentravam em espaços de alta circulação de pessoas, principalmente praças, avenidas e parques, com destaque para o Parque da Redenção, na região central da cidade.

As ocupações realizadas declaradamente como intuito de ressignificação ou reocupação do espaço urbano foram descritas por diversos participantes como uma espécie de 'quebra', com as formas padronizadas de viver na urbe. 
Em geral, foram descritas tanto como formas mais "afetivas e humanas" de interagir na cidade, como uma interlocução com o poder governamental que, em geral, era visto como representante de uma lógica higienista e positivista. Os participantes deste tipo de ocupação consideraram que ocupar o espaço por meio de ações coletivas poderia transformar a percepção das pessoas sobre locais da cidade, interferindo ativamente nas formas de significar determinado lugar.

Os locais escolhidos representam pontos chave da cidade. Espaços onde a memória social resiste a uma institucionalização de lógica capitalista da cidade, que transforma alguns locais - outrora palco de interação social - em não-lugares, em espaços não relacionais, marcadamente de trânsito, de passagem e de consumo. Ocupar, portanto, pode ser entendido aqui como um ato simbólico de transformar o espaço em lugar, naquilo que permite a troca de afetos, a construção de laços entre as pessoas, potencializando relações comunitárias entre os cidadãos. Não significa, portanto, que estes processos se deem necessariamente através do apelo de determinados pontos da urbe, dedicados a uma memória legitimada, mas, sim, através de espaços que assumem, por atribuição dos membros das comunidades, um caráter de apropriação, com potencial de reelaboração da simbologia dos acontecimentos neste espaço (NORA, 1997).

Estes locais, ao passo que desempenham o papel de espaços de interação pública (e são lembrados pelos entrevistados como tais), mostram que a marcação geográfica ilustra também elementos de marcação de fronteiras entre grupos com diferentes status sociais e poder econômico. Nas entrevistas, é recorrente o exemplo do Parque da Redenção e do Parque Moinhos de Vento reconhecidos como, respectivamente, locais de público diversificado e economicamente mais elitizado. Quando questionada sobre as rotas realizadas pelos eventos em que participou, em específico o Marcha das Vadias (Julho, 2013) a participante Clara ${ }^{2}$ comenta:

Eu achei interessante, principalmente por ser domingo, muitas pessoas estavam ali naquele lugar; mas não pela marcha, mas por estarem num lugar público. Eu acho que foi muito bem pensada a rota, passou pela Redenção, onde passa muita gente. Não querendo generalizar, mas se a marcha fosse na 24 de Outubro (uma das ruas do Parque Moinhos de Vento), seria um pouco estranha, seria muito mais julgada naquele espaço.

Muitas vezes, ao longo do processo etnográfico e realização das entrevistas, as ocupações foram descritas tanto como possibilidades de reivindicação 
de pautas sociais - meio de participação popular e ressignificação do espaço - mas também como forma de diversão menos engajada explicitamente. Em eventos cuja pauta era declaradamente promover um ambiente de socialização e ressignificação cultural dos espaços, mostram-se alguns marcadores de classe e território.

Marcha das Vadias, Parque da Redenção, Julho de 2013

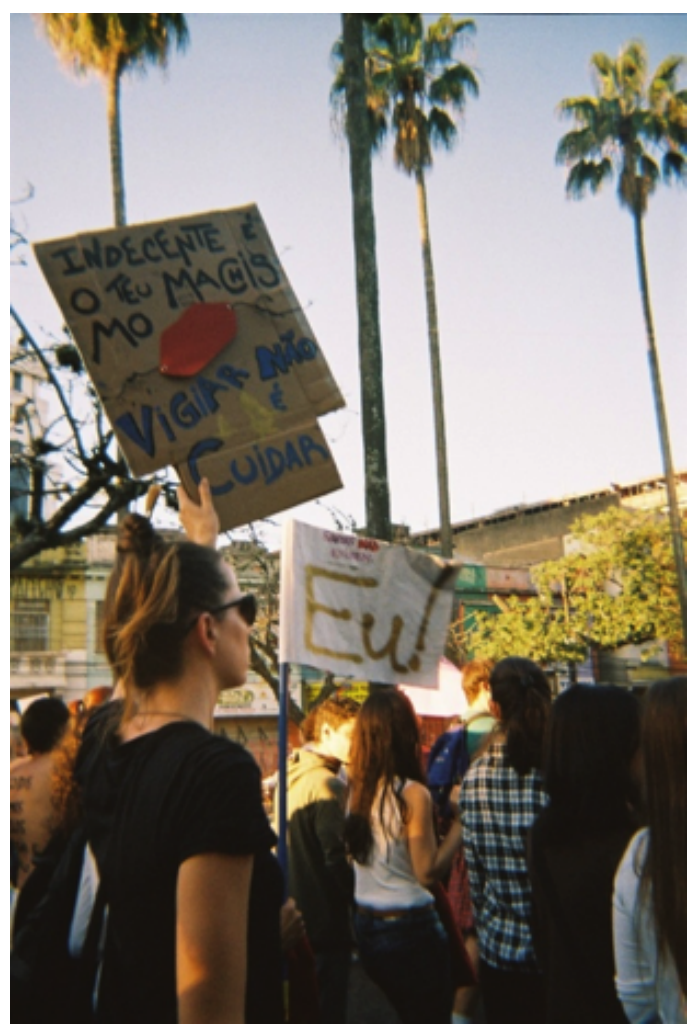

Fonte: arquivo dos pesquisadores

Em dois eventos desse tipo - um no Parque da Redenção e outro no Parque Moinhos de Vento - algumas questões emergiram:

Como é gratuito, a gente tem mais possibilidade de que todas as pessoas possam ter acesso, por exemplo, para entrar numa casa noturna, numa boate, sabe... esses espaços são pagos e são caros (Gustavo; "Piquenique Poético"; Parque da Redenção; Março de 2014). 
Piquenique Poético, Parque da Redenção, Março de 2014

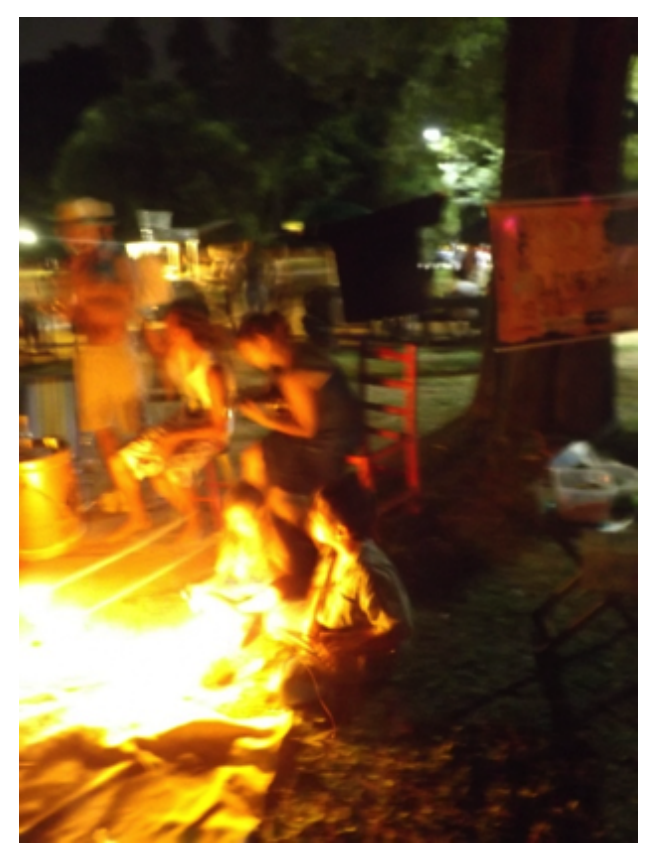

Fonte: arquivo dos pesquisadores

Eu acho que a gente tem que se voltar para essas coisas mais simples né, o mundo está muito 'do dinheiro', o que tu tens ou o que tu não tens. Se tu fores no parque todo mundo é igual. Talvez até pela marca de espumante que tu estás tomando possa fazer alguma diferença, mas ali sentado no parque, todo mundo é igual. (Juliana; "Piquenique Noturno no Parcão com os Chefs"; Parque Moinhos de Vento; Março de 2014).

Em todos os eventos, a internet foi o meio de comunicação utilizado para convite social - em especial o Facebook. Entretanto, há de se ressaltar que, no evento realizado no Parque Moinhos de Vento, a ênfase dada pela entrevistada foi na possibilidade de garantir segurança a partir de convites que se restringiriam aos 'amigos dos amigos' (uma das possibilidades de convite pelo Facebook). Este aspecto nos faz pensar nas interlocuções possíveis do espaço virtual como um espaço geográfico de socialização - quando interseccionado com aspectos territoriais, de classe e 'raça', por exemplo, ainda que aponte para outro aspecto importante: a reaproximação da classe média à urbe, enquanto lugar. O marcador 'raça' deve ser ressaltado, já que figurou em uma diferenciação bastante evidente nos diários de campo sobre eventos nas áreas Parque da Redenção/Moinhos de Vento. 
Considerando o número grande de participantes envolvidos no evento no Parque Moinhos de Vento, interpretamos que o critério de segurança para a entrevistada perpassa noções específicas de filiações confiáveis e de quem deve usar o território em específico:

\begin{abstract}
Isso, redes sociais, e a gente faz questão que continue assim, sabe? O amigo do amigo... tanto que nesse último evento tinha 25.000 convidados. Teus amigos convidam outros amigos, e assim vai... porque como a gente quer ocupar para pedir por maior segurança e iluminação, a gente também tem que se preocupar com a segurança. Eu acredito assim ó, que se for para a imprensa dizendo 'nós estamos fazendo isso' ai sim vamos ter problemas de segurança. (...) tanto é que na Serenata Iluminada (Parque da Redenção) teve assalto... por quê? Os malandros sabem que está sendo ocupado o parque (...) (Juliana; "Piquenique Noturno no Parcão com os Chefs"; Parque Moinhos de Vento; Março de 2014).
\end{abstract}

Tanto no mapeamento quanto nas entrevistas realizadas, a internet foi utilizada e referida como uma ferramenta de organização da ação. Muitas das manifestações e ocupações nas quais houve participação dos pesquisadores possuíam páginas e grupos nas redes sociais, por meio das quais convidavam os diversos manifestantes/ocupantes/militantes que delas participavam. Nessas páginas web constavam informações sobre os locais das ocupações, as ideias que pautavam as ações coletivas que as organizavam, assim como "instruções" sobre as possibilidades de ação localizadas nestas ocupações. Um ponto chama a atenção: não há assinatura ou proclamação de liderança individual na maioria dos eventos. Além das ações específicas, como o exemplo acima, os militantes de movimentos sociais mais formais que foram entrevistados falaram da importância da internet para que essa configuração pudesse acontecer.

Esse uso das TIC (celulares, aplicativos, fóruns, máquinas fotográficas, etc.) e, em especial, de ferramentas como o Facebook, leva à reflexão de que analisamos organizações que tomam forma de rede, devido ao papel das TIC sociais virtuais em sua concepção e organização. Assim, essa horizontalidade nas decisões e representações poderia ser vislumbrada como um dos desdobramentos da sociedade em rede a que Castells (2012) se refere, especialmente ao analisar movimentos semelhantes no hemisfério norte. Os próprios participantes de algumas ocupações de Porto Alegre também se referem à afiliação, identificação com pautas e fazeres dessas ações coletivas.

Entretanto, ainda que as TIC sejam indicadas como forma importante de divulgação e organização das ocupações urbanas, não figuram como o único meio de comunicação. Os cartazes e performances no decorrer das manifestações são indicados como fatores importantes para se passar determinadas 
mensagens - em especial quando as ocupações colocam como pauta principal alguma reivindicação política. Este tipo de uso de divulgação parece indicativo da ênfase dada na ocupação do espaço urbano concreto (não só virtual), assim como da preocupação em passar uma mensagem coerente para os transeuntes e a mídia formal:

Muitas vezes ali, no grito, as pessoas não conseguem ouvir. Lendo os cartazes 'mulher não pode mais apanhar', ou 'sou homem mas sou feminista' ... às vezes não se consegue ouvir o grito, mas o cartaz serve para mostrar as ideias. O cartaz é uma forma de publicidade da marcha em si. Tanto as pessoas da mídia como as pessoas de fora conseguem enxergar com clareza. E até um pouco de ironia, que fica também mais divertido (Clara; "Marcha das Vadias"; Parque da Redenção; Julho de 2013).

Também se evidencia, em algumas entrevistas, uma compreensão das ocupações como um fenômeno mundial que ganhou força e adesão a partir de manifestações divulgadas internacionalmente e, principalmente, que mudou a visão da população sobre os manifestantes no Brasil a partir da repercussão de movimentos sociais similares em outros países.

Se isso acontecesse antes da Primavera Árabe, não teria gente na rua. Mas a partir do momento em que se viu mudanças em países europeus, a partir do momento em que os rebeldes daqui foram vistos da mesma forma que os ativistas da Europa, o povo começou a ir pra rua. (Silvana; "Marcha das Vadias"; Parque da Redenção; Julho de 2013).

Menções ao caráter internacional das ocupações e a posição de países estrangeiros como referência aparecem na fala de outros participantes:

\footnotetext{
“(...) o espaço é nosso, nós pagamos impostos, a gente quer mais retorno das coisas, nós estamos no século XXI, nós estamos vinte anos atrasados em relação aos movimentos que acontecem na Europa, nos Estados Unidos... né? Chega! (Sandro; "Piquenique Noturno no Parcão com os Chefs"; Parque Moinhos de Vento; Março de 2014).
}

Entretanto, nos parece que para além das referências internacionais estarem presentes em ambas as falas - assim como em outras entrevistas e conversas ao longo do processo etnográfico - compreendemos que o teor do conteúdo difere e coexistem algumas questões. Primeiramente, o caráter de referência explícita aos países considerados, desenvolvidos em duas facetas: como exemplo de vanguarda, ou como imagem que dá crivo ao brasileiro 're- 
belde' transformado em manifestante. Para além do manifestante engajado de forma mais coerente com a visão tradicional dos movimentos sociais - jovem, com pautas específicas e itinerário militante organizado, como aparece em muitas entrevistas -, quando abrimos espaço para analisar as ocupações como um todo, vemos uma variedade de participantes, dependendo das temáticas emergentes.

Quando as pautas são a ocupação do espaço como forma de ressignificar a sua utilização - o resgate do lugar público - a população envolvida foi, por vezes, indicada como mais 'diversa'. Em alguns eventos esse fator foi declaradamente planejado, como indica a fala de Juliana:

\begin{abstract}
Aqui no Parcão (Parque Moinhos de Vento) tem muito mais família, na Redenção tem muito mais gurizada assim que nem tu assim (risos). Só que a gente achou muito mais legal no Parcão por ter essa mistura, de ter velhos, ter jovens, e as pessoas de meia idade - e ter tudo entende? E na Redenção não parece ter isso (...) no Parcão não. Isso foi bacana, tinha de tudo. Tinha de 0 , bebê, até os 90 . Até o Cônsul e a Consulesa da Alemanha estavam lá. Tinha um grupo de espanhóis também que ficaram sabendo que tinha Piquenique, tava bem diversificado né! (Juliana; "Piquenique Noturno no Parcão com os Chefs"; Parque Moinhos de Vento; Março de 2014)
\end{abstract}

Na ocupação supracitada, a preocupação com , enquanto sinônimo de segurança e proteção, emergiu nas entrevistas realizadas, em especial como uma justificativa para a manutenção de um evento entre 'conhecidos', ou seja, onde uma afiliação comunitária podia ser percebida, especialmente pelo status social. Entretanto, a percepção de participantes de outras ocupações sobre o policiamento, por exemplo, parece diversa. Em uma entrevista com Manuel, no evento Piquenique Poético no Parque da Redenção, ele dá um exemplo do que compreende ser uma das facetas do policiamento, lembrando-se da ocupação do espaço em frente ao central Bar do Tuti (um bar atualmente inativo), frequentado principalmente por universitários e coletivos menos elitizados economicamente:

Tinha PM, tinha Brigada Militar no TUTI, tá ligado? Privatizando nosso espaço. Naquele dia, eu posso comprovar, porque eu vi amigos indo pra lá e voltando, porque a Brigada Militar estava lá... Não é privatizar um espaço? É privatizar um espaço! (Manuel; "Piquenique Poético"; Parque da Redenção; Março de 2014).

Para os pesquisadores parece interessante notar essa relação com a polícia, principalmente quando falamos de um lugar cujo público possui 
marcadores como juventude. Essa questão remeteu, em discussões dos pesquisadores sobre percepções no processo etnográfico, a memória da figura romantizada do militante político no Brasil - tradicionalmente, jovem e universitário.

Parece interessante tomar as ações coletivas aqui discutidas como possibilidades de oferecer experiências subjetivas de qualidade política - sejam mais voltadas para o que se pode reconhecer como happenings (HAMANN et. al, 2013), seja como ocupações com pautas mais estáveis. Num paralelo com as discussões elaboradas por Rancière (2010) - quando toma a noção de política como eminentemente transformadora e criativa - podemos compreender esse processo de ocupação dos espaços públicos, ou ao menos a emergência desta temática como pauta popular, enquanto possibilidade de dissensos emancipatórios. Ao transformar os espaços e retomá-los em sua configuração de lugares, os indivíduos criam discussões e rompem com o silêncio que estabiliza o status quo, permitindo que surja o dissenso.

Pedalada Pelada, Largo Zumbi dos Palmares, Dezembro de 2013

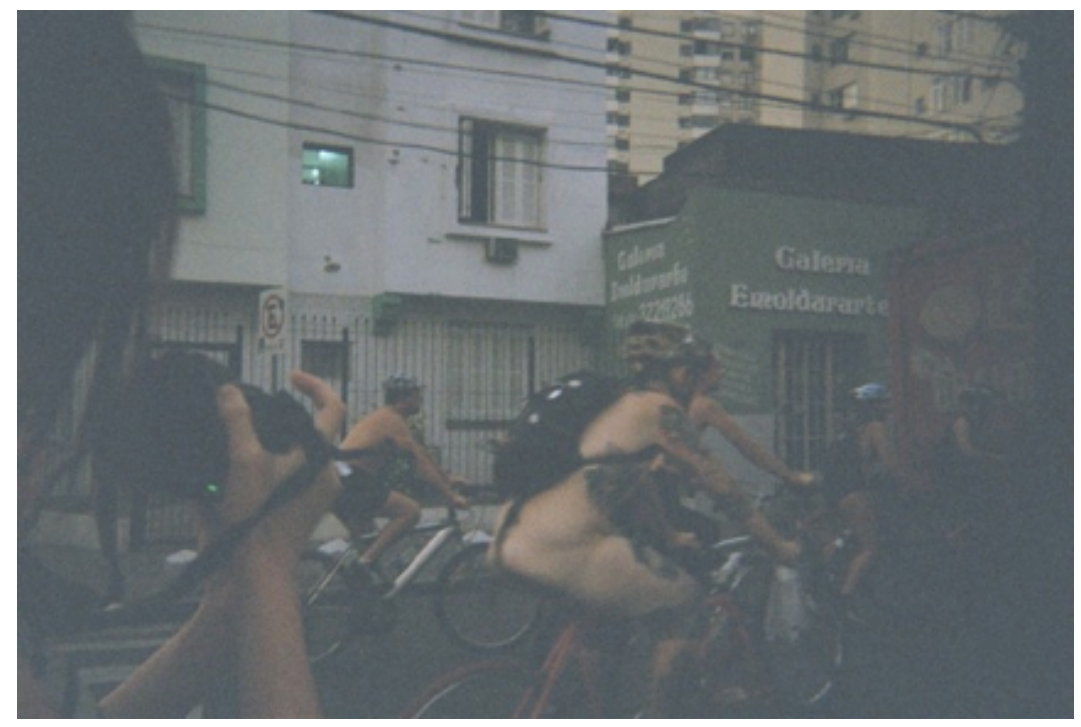

Fonte: arquivo dos pesquisadores

É inegável relacionar o processo de transformação da ocupação urbana em pauta popular e, posteriormente, acadêmica, com as manifestações de Junho de 2013 em todo o Brasil. Apesar do período ter sido alvo de várias interpretações, é notável como historicamente marcam as ocupações do espaço público no Brasil, e interpelam leituras tradicionais de movimentos sociais. Os diários de campo da equipe de pesquisa atentam para a sen- 
sação de diversidade de pautas a cada dia de manifestação e ao longo das ocupações nas ruas de Porto Alegre. Era possível conversar com diversos participantes que, ou se identificavam com pautas bastante diversas no mesmo evento, ou se uniam em uma temática mais generalista, como o fim da corrupção no Brasil.

Esta noção de potência social, em especial marcada pela sensação de partilha ao fazer parte das multidões pela cidade, era indubitavelmente circunscrita a uma pluralidade de pautas. $\mathrm{O}$ valor da tarifa de ônibus, o fim da corrupção, o fim dos partidos políticos, o cancelamento de jogos da Copa das Confederações na cidade e reformas políticas foram pautas possíveis de se encontrar, intercambiando-se ao longo de uma mesma avenida de Porto Alegre. Ao passo que podem remeter a uma falta de organização e efetividade para alcançar determinados objetivos políticos - em especial na recorrente referência a governantes e à falta de lideranças para diálogo - é importante o impacto que estas manifestações podem ter quando se trata de ressignificar os espaços em geral usados para circulação, assim como colocar em evidência as alteridades presentes como possibilidade de existência social. Segundo Augé (1992), a noção de espaço e urbanidade está intrinsecamente relacionada à de alteridade, de modo que o afastamento do outro - em detrimento de vivências solitárias - é uma tensão constante na contemporaneidade.

A noção de diálogo dos governantes, que se puseram impactados com a falta de figuras de liderança, pode nos remeter à falta de interlocução da representação política com a participação coletiva nas ocupações. Considerando os adjetivos utilizados pelos governantes na mídia para definir os eventos como "desorganizados", podemos considerar como possibilidades de interpretação a falta de compreensão ou a busca por descrédito e depreciação de grande parte destes atos - principalmente com aqueles que utilizam de certa proximidade com atos violentos. Conforme aponta Castells (2012), a liberação de imagens, os debates e os chamamentos por parte dos manifestantes vai agregando pessoas de forma horizontal, gerando identificações e, assim, possibilitando as ações coletivas. Essa problemática em relação ao diálogo e a ausência de lideranças indicada por governantes se evidencia com o uso expressivo das redes de comunicação na internet, que colocam em questão a figura das lideranças personalizadas.

Esta aparente falta de liderança nos moldes tradicionais é um dos aspectos que trouxeram para o debate acadêmico a necessidade de se rediscutir o conceito de movimento social, uma vez que a ação em rede tensiona realocações nas práticas de negociação das reivindicações junto aos poderes públicos. $\mathrm{O}$ caráter inovador desse formato de ação pode ser compreendido, em parte, pela descredibilidade dos representantes institucionalizados que atuam na política 
partidária nacional. A postura contrária ao representacionismo partidário também surge como elemento característico dessas ações. Tal condição apartidária produz discussões entre os integrantes da ação coletiva: alguns optam pela participação formalizada dos partidos e defendem que, destes, surjam representantes da ação, enquanto em outro polo aparecem aqueles que defendem que a presença dos partidos reproduz o "sistema falido e genérico" que eles questionam.

\section{Considerações finais}

A aproximação do universo das ações coletivas e movimentos sociais na cidade de Porto Alegre foi um desafio, não apenas como pauta de discussão da organização social contemporânea, mas também um desafio ético e metodológico. Além da óbvia e necessária inserção no campo direto - observando, acompanhando e integrando as ações - contar com o "olhar" e a "voz" direta dos participantes através de suas reflexões fotográficas e discursivas foi realmente um diferencial na discussão e análise desse processo.

Além disso, a pesquisa aproxima suas reflexões às de outros pensadores da contemporaneidade, em especial as de Rancière (2010) e Castells (2012), que veem nas ações e movimentos sociais atuais mais do que uma "nova forma de protestar", mas uma nova forma de ser, de afiliar-se e de relacionar-se com $a$ e $n a$ urbe atual. Mais do que uma nova forma de agir, pode-se pensar nessas ações de ocupação da cidade como um aforismo de uma nova ontologia do social - onde os processos identificatórios oscilam do local ao global, do coletivo ao hiperindividual. Ocupar a cidade pode ser ocupar-se de si mesmo, em um embate micropolítico que pode ir além, questionando certezas aparentemente consolidadas sobre o que se acreditava ser consenso - como as noções de liderança, democracia, participação e representatividade, por exemplo.

Evidentemente, nos referimos aqui a uma nova forma de fazer política; de encontrar, na intersecção desses múltiplos dissensos (locais/globais; coletivos/individuais...), as brechas necessárias para a criatividade e a reinvindicação de algo novo, de uma nova forma e por motivos diferentes das leituras predominantes. Essa nova "militância" nem sempre se identifica com esse ou com qualquer outro rótulo, nem sabe se quer (ou se requer) identificar-se ou pertencer a um "movimento" (em uma leitura mais institucionalista). Mas se movem e movimentam a cidade. Principalmente, movem o foco da atenção da urbe para os outros lados de si mesma, para as muitas periferias (ou os muitos não centros), para seus não-lugares, para suas sombras e seus duplos.

As reflexões apontadas pelos participantes nos diferentes contextos de análise, fomentam a discussão sobre que ações, por parte da comunidade e do poder público, podem ser (re)pensadas a fim de estabelecer relações mais 
horizontalizadas e menos punitivas, que compreendam os direitos dos cidadãos e promovam ações críticas sobre a realidade. Os resultados explicitam os processos dialógicos que ocorrem nessas manifestações e que contam com a contribuição de vários fatores psicológicos, culturais e históricos. Dentre estes, os elementos comunicacionais e identitários típicos da globalização contemporânea parecem configurar a tônica de muitas dessas ações. O estranhamento apontado pela mídia e a necessidade de complementação dos referenciais de análise tradicionais validam a necessidade de novas reflexões sobre as ações e movimentos sociais contemporâneos, nos quais as tecnologias de informação e comunicação parecem tomar um papel ainda não totalmente compreendido.

\section{Referências}

AUGÉ, Marc. Não-lugares: Introdução a uma antropologia da supermodernidade. Trad. Maria Lúcia Pereira. Campinas: Papirus, 2011. 112 p.

. Non-lieux: introduction à une anthropologie de la surmodernité. Paris: Seuil, 1992. 160 p.

BANKS, Marcus. Dados visuais para pesquisa qualitativa. Trad. José Fonseca. Porto Alegre: Artmed, 2009. 176 p.

BAUMAN, Zygmund. O mal-estar da pós-modernidade. Trad. Mauro Gama et al. Rio de Janeiro: Zahar, 2009. 272 p.

Identidade: entrevista a Benedetto Vecchi. Trad. Carlos Alberto Medeiros. Rio de Janeiro: Zahar, 2005. 110 p.

CARNEIRO, Henrique Soares. Rebeliões e ocupações de 2011. In: HARVEY, D. et al. (Eds.) Occupy: movimentos de protesto que tomaram as ruas. Trad. João Alexandre Peschanski et al. São Paulo: Boitempo, 2012, p.7-14.

CASTELLS, Manuel. A Sociedade em Rede: A Era da Informação: economia, sociedade e cultura. Trad. Roneide Venâncio Majer. São Paulo: Paz e Terra, 2012. 698 p.

DIANI, Mario. The Concept of Social Movement. The Sociological Review, Keele, v. 40, n. 1, p. $1-25,1992$.

FLICK, Uwe. Introdução à pesquisa qualitativa. Trad. Elias Costa. Porto Alegre: Artmed, 2009. $405 \mathrm{p}$.

HAMANN,Cristiano; MARACCI-CARDOSO,JoãoGabriel;TEDESCO,Pedro;VISCARDI, Fabrício. Movimentos de ocupação urbana: uma integração teórica através do conceito de happening. Diálogo, Canoas, n. 23, p. 19-33, 2013.

HARVEY, David. et al. Occupy: movimentos de protesto que tomaram as ruas. Trad. João Alexandre Peschanski et al. São Paulo: Boitempo, 2012. 86 p. 
HIERNAUX, Daniel. Repensar a cidade: a dimensão ontológica do urbano. GEOUSP - Espaço e Tempo, São Paulo, n. 20, p.197-205, 2006.

LEITE, Jáder Ferreira.; DIMENSTEIN, Magda. La intervención de los movimientos sociales en el área rural brasilera: cartografiando el Movimiento de los Trabajadores Rurales Sin Tierra (MST). In: SAFORCADA, E. et al. (Orgs.). Aportes de la Psicología Comunitaria a problemáticas de la actualidad latinoamericana. Buenos Aires: JVE Editores, 2007, p.153-166.

LIPOVETSKY, Gilles. A felicidade paradoxal: ensaio sobre a sociedade de hiperconsumo. Trad. Maria Lucia Machado. São Paulo: Companhia das Letras, 2007. 402 p.

LOPES, Gustavo Chaves. Redes Sociais, Emancipação Política, desobediência civil e mobilização: resgatando o pensamento de Kant e Thoureau. Cadernos de Comunicação, Santa Maria, v. 17, n. 2, p. 215-231, jul./dez. 2013.

MATTELART, Armand. Diversidad cultural y mundialización. Barcelona: Paidós Comunicación, 2005. 177 p.

MAURENTE, Vanessa.; TITTONI, Jaqueline. Imagens como estratégia metodológica em pesquisa: a fotocomposição e outros caminhos possíveis. Psicologia \& Sociedade, Porto Alegre, v. 19 , n. 3, p.33-38, 2007.

MINOIS, Georges. História do riso e do escárnio. São Paulo: Unesp, 2003. 654 p.

NORA, Pierre. Les lieux de mémoire. Paris: Gallimard, 1997. 1652 p.

PIZZINATO, Adolfo. Psicología e imágenes: el proceso de narración digital en la investigación sobre la identidad en la infancia en riesgo de exclusión. Hallazgos, Bogotá, n. 10, p. 55-63, 2008 .

RANCIÈRE, Jacques. El espectador emancipado. Buenos Aires: Manantial, 2010. 130 p.

SA, Teresa. Lugares e não lugares em Marc Augé. Tempo soc. [online]. 2014, v.26, n.2, pp. 209-229.

UGLIONE, Paula; DUARTE, Cristiane. Arquivos Urbanos: Memória e História na Cidade. Quaderns de Psicologia, Barcelona, n. 1, v. 13, p. 91-101, 2011.

VIRILIO, Paul. O espaço crítico. Trad. Paulo Roberto Pires. São Paulo: Editora 34, 1993. 124 p.

WAISBICH, Laura Trajber. Manifestejos de junho: negação e ocupação da coisa pública. Jornal de Psicanálise, São Paulo, v. 46, n. 84, 2013. Disponível em: < $\underline{\text { http://pepsic.bvsalud.org/ }}$ pdf/jp/v46n84/v46n84a14.pdf> Acesso em: 9 fev. 2015.

Submissão em: 10/02/2015

Revisão em: 19/05/2015

Aceite em: 04/01/2016 
Adolfo Pizzinato é doutor em Psicologia da Educação pela Universitat Autònoma de Barcelona. Mestre em Psicologia Social e da Personalidade e graduado em Psicologia pela Pontifícia Universidade Católica do Rio Grande do Sul. Professor da Faculdade de Psicologia e do Programa de Pós-Graduação em Psicologia da PUCRS. Endereço para correspondência: Av. Ipiranga, 6681, prédio 11, sala 930. CEP: 90616-900. Porto Alegre/RS, Brasil. E-mail: adolfo.pizzinato@pucrs.br

Cristiano Hamann é doutorando pelo Programa de Pós-Graduação em Psicologia Social e Institucional da Universidade Federal do Rio Grande do Sul (UFRGS). Mestre em Psicologia Social pela Pontifícia Universidade Católica do Rio Grande do Sul (PUCRS - bolsa de pesquisa CNPq). Graduado em História pela Universidade Luterana do Brasil (ULBRA). Graduação em andamento em Psicologia pela Pontifícia Universidade Católica do Rio Grande do Sul (PUCRS).

E-mail: chamann13@,hotmail.com

Ezequiel Simonetti Cargnelutti é graduando em Psicologia pela Pontifícia Universidade Católica do Rio Grande do Sul. Bolsista de Iniciação Científica (BPA-PUCRS) pelo grupo Identidades, Narrativas e Comunidades de Práticas (INCP).

E-mail: ezequielcargnelutti@gmail.com

Roberta Iankilevich Golbert é graduanda em Psicologia pela Pontifícia Universidade Católica do Rio Grande do Sul. E-mail: roberta.golbert@acad.pucrs.br

Lígia Burton-Ferreira é graduanda em Psicologia da PUCRS. E-mail: ligiaburton@gmail.com

Rodrigo Oliveira-Machado é doutorando em Psicologia Social, Universitat Autònoma de Barcelona. Mestre em Psicologia Social e graduado em Psicologia da Pontifícia Universidade Católica do Rio Grande do Sul. E-mail: rodrigo.psicopuc@gmail.com 